\section{Job Prospects for Political Scientists: Placement Experience in 1995}

\section{Michael Brintnall, APSA}

Job prospects for new political science doctoral students continue to be of great concern. As Anne C. Petersen, deputy director of the National Science Foundation, has said about the job market for new scientists: "The anxiety some young people have is really palpable" (Magner 1996b, A19).

Recent findings on placement experience for doctoral graduate students in political science send a mixed message about the state of the job market in political science. While there is evidence that the market is continuing to tighten, results from job candidates in political science seeking placement last year do not show any dramatic differences from placement experience over the last decade. Overall, $72 \%$ of students on the job market in spring of 1995 were placed, a higher rate than the year before and better than most recent years.

This report examines the placement success of Ph.D. and ABD students in political science on the job market during academic year 1994-95. Information for this report is taken largely from a recent survey of graduate placement directors regarding the job search experiences of their students.

Overall, some summary characteristics of the placement last year are the following:

- The placement class was somewhat smaller than the preceding year, though still larger than has typically been the case in the last decade;

- The proportion of students searching for positions who had been on the job market the year before continues to be high;

- More job applicants than ever were on the market before having completed their doctorate. Only $56 \%$ of job seekers last year had the $\mathrm{Ph} . \mathrm{D}$. in hand, compared to about two-thirds a decade ago;

- Placement success for students with the Ph.D. in hand is substantially greater than for those who are ABD: $85 \%$ of Ph.D. holders found positions last year compared with $56 \%$ of ABD's;

- Men and women found positions at about the same ratethough men are somewhat more likely to be placed in temporary positions than women;

- Placements in nonacademic positions are increasing gradually, though are still a small share (13\%) of jobs taken.

\section{The Placement Class}

APSA obtains its information about placements from a survey of graduate placement directors in political science departments in Ph.D.-granting institutions. The placement class represents all students completing or nearing completion of the doctoral programs and actively looking for a job. This year, 95 doctoral programs responded to the survey, for a $73 \%$ response rate. This respondent pool included all of the large doctoral programs, which historically have had the biggest placement classes, and so we have not adjusted actual numbers for missing cases.

This year, 799 students were identified in the placement class, compared to 1,037 last year and an average of about 700 in previous years. Even making various estimates about non-responding schools, this year's placement class is not as large as last year, but continues to be bigger than other years in the past decade.

A trend continued with this placement class to include more students repeating their job search from the previous year, and more students without the Ph.D. yet in hand. This appears to be both a sign of increased difficulty in landing positions, and perhaps a strategic move on the part of some students to search for jobs earlier, and probably thus longer. Just $56 \%$ of the students on the market had the Ph.D. in hand, down from 64\% a decade earlier. This information is shown in Table 1.

Schools reporting the largest numbers of students on the market last year-ranging from 22 to 38 candidates-include Princeton, Chicago, Michigan, Harvard, Ohio State, Cornell, Boston University, and North Carolina at Chapel Hill. MIT, University of California, Berkeley, Wisconsin, University of Southern California, Indiana, and other schools also reported large placement classes. The mean number of students from each institution seeking placement is about eight.

\section{Placement Success}

Under any circumstances, a snapshot of the academic placement market shows a difficult and potentially tension-laden process. In any one year, only about $70 \%$ of new job seekers on the academic job market will find a position at that time-based on average data from the last 14 years. Thirty-five percent of new job seekers historically-half of those finding an academic position-will find temporary employment at best.

Put differently, based on experience over the last decade and a half, in any one year only about two-thirds of job seekers will find academic or relevant nonacademic employment, and just one-third of job seekers newly out of graduate
TABLE 1

Trends in Placement*

\begin{tabular}{lrrrrrrrr}
\hline & 1982 & 1984 & 1986 & 1988 & 1990 & 1992 & 1994 & 1995 \\
\hline Number of firm candidates & 611 & 672 & 690 & 740 & 823 & 763 & 1037 & 799 \\
\% repeats & 36 & 38 & 32 & 32 & 32 & 33 & 40 & 41 \\
\% Ph.D. & 64 & 64 & 69 & 64 & 59 & 59 & 59 & 56 \\
\% women & 21 & 25 & 26 & 25 & 26 & 30 & 27 & 28 \\
\hline
\end{tabular}

*Figures are from 91 departments for 1982 (76\% response rate), 83 departments for 1984 ( $71 \%$ response rate), 83 departments for 1986 (70\% response rate), 115 departments for 1988 (92\% response rate), 118 departments for 1990 (93\% response rate), 110 departments for 1992 ( $87 \%$ response rate), 106 departments for 1994 ( $81 \%$ response rate), and 95 departments for 1995 ( $73 \%$ response rate) 


\begin{tabular}{|c|c|c|c|c|c|c|c|c|}
\hline $\begin{array}{l}\text { TABLE } 2 \\
\text { Placement Success* }\end{array}$ & & & & & & & & \\
\hline & 1982 & 1984 & 1986 & 1988 & 1990 & 1992 & 1994 & 1995 \\
\hline Overall & 62 & 72 & 69 & 69 & 72 & 74 & 69 & 72 \\
\hline Ph.D. & 68 & 77 & 83 & 83 & 78 & 79 & 82 & 85 \\
\hline A.B.D. & 55 & 68 & 57 & 53 & 63 & 66 & 50 & 56 \\
\hline Men & 61 & 72 & 67 & 70 & 73 & 73 & 67 & 72 \\
\hline Women & 64 & 71 & 74 & 67 & 70 & 75 & 74 & 71 \\
\hline $\begin{array}{l}\text { Percent placed in } \\
\text { temporary positions }\end{array}$ & 36 & 33 & 38 & 38 & 21 & 32 & 29 & 34 \\
\hline Men & 37 & 33 & 38 & 38 & NA & 34 & 29 & 36 \\
\hline Women & 36 & 34 & 35 & 33 & NA & 28 & 29 & 31 \\
\hline
\end{tabular}

school in political science will find a tenure track (or comparable nonacademic) position. We know of course that many job searches extend over several years, that temporary positions sometimes are transformed into permanent ones, and so forth. Data from a snapshot of one year of the job market is not comparable to the experience any individual candidate might have over the course of their complete job search.

From the perspective of these baseline numbers from the last decade and a half, however, the job market for new political scientists last year was not much different from past years. Seventy-two percent of new political scientists on the market last year reportedly found a position-a comparable or better rate than that experienced in almost any year in the last decade. For students with the Ph.D. in hand, this was the best year ever in that period, with $85 \%$ finding placement. However, just $56 \%$ of students who are ABD found positions-a rate at the low end of the last decades' experience.

Just over a third of all candidates found temporary positions-typically one-year appointments. This too is within the range of experience of the last decade, though at the high end. These numbers are about the same whether the candidate has the Ph.D. in hand or not. That is, having a Ph.D. completed is a distinct advantage in landing academic employment in political science, but it offered no edge over those who are still ABD in whether the appointment is tenure track or not.

\section{Field of Specialization and Type of Institution Hiring}

Placement success was strong in almost every major field of political science. Over half of the placements were in comparative or international relations, and over a quarter were in American government. The international relations (IR) and comparative politics fields grew as a share of all positions filled, relative to American government and other fields. But placement success in comparative politics was a little lower than average, suggesting this field is a bit more competitive. A larger share of the positions in IR (39\%) were nontenure track than other fields.
Some placement directors the year before had said they saw American politics as a growth field. This year placement did remain strong with over three-quarters of job applicants in this area finding positions.

Public policy and public administration, while a relatively small share of all positions, had the strongest placement success, with over $82 \%$ of students in those fields finding positions. This is explained in part by a higher rate of placement of public policy students in nonacademic jobs, but even looking just at academic hires, these fields showed high placement success. Public administration was most successful in offering up permanent positions-only $14 \%$ of the 29 placements in this field were temporary.

Perhaps the most difficult field for placement is political theory. Placement in political theory last year was especially tight, with only $56 \%$ of applicants in this field finding positions. Only $9 \%$ of all jobs filled last year were in political theory, compared to $13 \%$ the year before. There were no placements reported at all in methodology, which has always been a minuscule part of the placement market.

Typically, Ph.D. departments
TABLE 3

Placement Success by Field of Specialization, 1986-95 (\%)

\begin{tabular}{|c|c|c|c|c|c|c|}
\hline & \multicolumn{6}{|c|}{ Total } \\
\hline & 1986 & 1988 & 1990 & 1992 & 1994 & 1995 \\
\hline \multicolumn{7}{|l|}{ Placement Success ${ }^{\mathrm{a}}$} \\
\hline American Government & 86 & 74 & 71 & 78 & 74 & 76 \\
\hline Public Policy & 95 & 82 & 74 & 78 & 80 & 82 \\
\hline Comparative/Area Studies & 65 & 63 & 74 & 77 & 69 & 69 \\
\hline International Relations & 54 & 65 & 71 & 68 & 63 & 73 \\
\hline Public Administration & 80 & 77 & 74 & 77 & 79 & 86 \\
\hline Political Theory & 73 & 59 & 61 & 70 & 61 & 56 \\
\hline Methodology & 100 & 100 & 83 & 50 & 50 & - \\
\hline \multicolumn{7}{|l|}{ Percentage of Those Placed ${ }^{b}$} \\
\hline American Government & 29 & 23 & 21 & 25 & 31 & 28 \\
\hline Public Policy & 8 & 6 & 6 & 6 & 5 & 6 \\
\hline Comparative/Area Studies & 25 & 26 & 28 & 27 & 25 & 27 \\
\hline International Relations & 18 & 19 & 25 & 23 & 19 & 24 \\
\hline Public Administration & 5 & 6 & 5 & 4 & 4 & 5 \\
\hline Political Theory & 12 & 12 & 10 & 13 & 13 & 9 \\
\hline Methodology & 1 & 2 & 1 & 0 & 0 & 0 \\
\hline Other & 2 & 7 & 4 & 2 & 3 & 2 \\
\hline
\end{tabular}


TABLE 4

Placement by Type of Hiring Institutions, 1986-95 (\%)

\begin{tabular}{lcccccr}
\hline & \multicolumn{7}{c}{ Total } \\
\cline { 2 - 7 } & 1986 & 1988 & 1990 & 1992 & 1994 & 1995 \\
\hline Ph.D. department & 41 & 40 & 41 & 45 & 42 & 39 \\
M.A. department & 16 & 17 & 16 & 11 & 14 & 16 \\
Undergraduate political science or & 32 & 33 & 32 & 31 & 31 & 30 \\
$\quad$ combined & 1 & 2 & 2 & 2 & 2 & 2 \\
Two-year college & 9 & 8 & 10 & 10 & 11 & 13 \\
Nonacademic & 99 & 100 & 101 & 99 & 100 & 100 \\
Total & & & & & & \\
\hline
\end{tabular}

have accounted for over $40 \%$ of hires- $42 \%$ on average. This year, the share of positions in Ph.D. institutions declined to $39 \%$. The share of jobs going to undergraduate institutions also was the lowest it has been in recent years at $30 \%$. On the other hand, positions are relatively more likely to be found in M.A. departments than has been the case in the last several years, and increasingly to be found outside academia.

Two percent of placements, 10 individuals, accepted positions in two-year institutions-community colleges and the like. Half of these job candidates had the Ph.D. in hand and half were ABD (roughly the same as the pool as a whole); seven were men and three were women (also roughly the same proportion as the pool as a whole). While these jobs can often be assumed to call for teaching across many political science fields, the academic fields of these individuals spread across American government, comparative politics, IR, public policy, and political theory. Almost all of these placements in two-year institutions were reported as temporary.

Nonacademic positions account for $13 \%$ of this year's placement, a rate that has grown gradually from around $9 \%$ a decade ago. Students in all fields took nonacademic placement, though, as noted, public policy students disproportionately took these jobs. Of people taking jobs outside academia, about a quarter were students in American politics, a fifth each in comparative politics and IR, and a tenth in political theory.

\section{Women and Minorities on the Job Market}

The Chronicle of Higher Education reports that "a new generation of professors is markedly changing the face of academe. . . . these faculty members are much more likely to be women and somewhat more likely to be members of minority groups." The report is based on a study recently conducted by the New Jersey Institute for Collegiate Teaching and Learning at Seton Hall University. They add that "fully a third of the country's fulltime professoriate belongs to this new group . . . contradicting the widespread perception that a weak academic job market has prevented a significant infusion of new blood" (Magner 1996b, A17).

These findings are no surprise in political science, which has shown steady increases in numbers and rank of women in the professoriate and enrolled in graduate study, and to a lesser degree (as found in the New Jersey Institute study for academe as a whole) increases for minorities (Brintnall 1992, 105);

(Spellman 1995, 319).

What is especially encouraging is that placement data show that women and minorities who are on the job market in political science are faring as well as their male and white counterparts. Women are $28 \%$ of the placement class-about a three percentage point increase over a decade ago. The women in the placement class are slightly less likely than men to have the Ph.D. in hand (51\% vs. $58 \%)$ and to be repeats. But placement rates are comparable-both for candidates with the Ph.D. and for the whole pool. Women are a bit less likely to be placed in temporary positions than men.

By field and type of placement there are little differences between the pools of men and women. Women are slightly more likely to be studying in public policy and

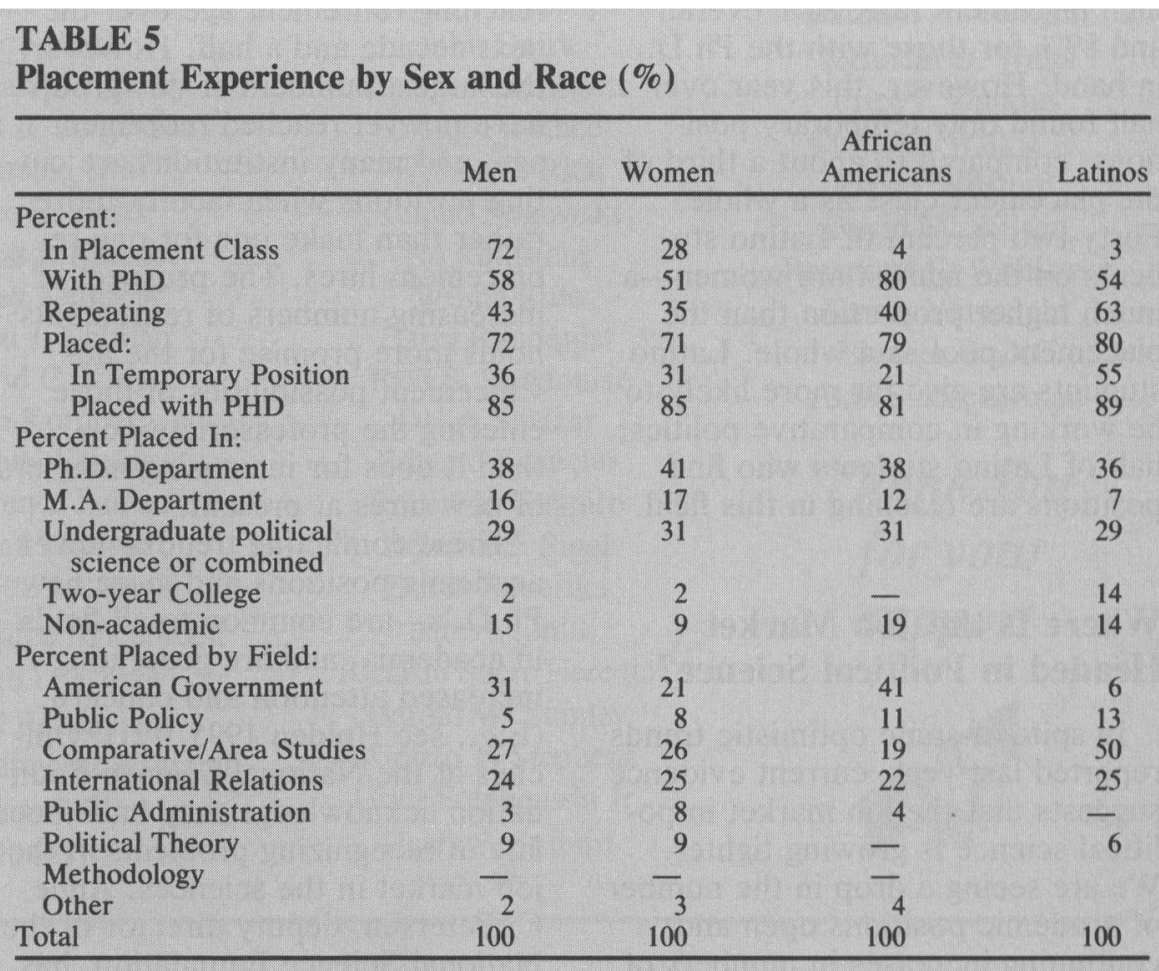


public administration than men, but less likely to take nonacademic jobs; only half the proportion of women studying public policy took nonacademic positions than men in that field.

African American students are $4 \%$ of the placement class, a slight drop from previous years. African American candidates seeking jobs are much more likely than others to have the Ph.D. in hand. Fully $80 \%$ had completed their degree, compared to $59 \%$ percent for the pool as a whole. This pattern has occurred in previous years as well, but not to this degree. Thirty-seven percent of the African Americans in the placement class are women, compared to $28 \%$ of the class overall.

Placement rates for African American students overall are higher than for others- $79 \%$ of those on the market found positions. A relatively higher percentage of the jobs were permanent. Comparing only job seekers who have completed the Ph.D., a slightly smaller percentage of African American job candidates were placed than for all candidates $(81 \%$ vs. $85 \%$ ).

Latino students are $3 \%$ of the placement class, a steady rate in recent years. This small pool has a high placement rate, $80 \%$ overall and $89 \%$ for those with the Ph.D. in hand. However, this year over half found only temporary positions, compared to about a third of the placement class as a whole. Forty-two percent of Latino students on the market are women-a much higher proportion than the placement pool as a whole. Latino students are also far more likely to be working in comparative politics; half of Latino students who find positions are teaching in this field.

\section{Where Is the Job Market Headed in Political Science?}

In spite of some optimistic trends reported last year, current evidence suggests that the job market in political science is growing tighter. We are seeing a drop in the number of academic positions open and continuing increases in numbers of graduate students entering doctoral programs and in Ph.D.'s awarded.

For the current year, academic job openings have shown a sharp drop. Numbers of job listings in the APSA Personnel Service Newsletter for academic year 1995-96 have dropped about $14 \%$ over the numbers in the last several years; and estimates of net new hires made by chairs in the APSA Survey of Political Science Departments for 1995-96 are down 11\% over the previous year. Expected hires to replace departing faculty are down by $15 \%$.

At the same time, political science graduate programs are producing increasing numbers of students. Enrollments in political science doctoral programs have increased by almost $30 \%$ the last decade, and annual Ph.D. production is up by about a quarter. In 1995, 876 Ph.D.'s were reported by doctoral programs in political science, public policy, and international relations, of which 760 were in the traditional political science doctoral programs that APSA has tracked over the years. In 1985, 614 degrees were awarded by these same programs.

What about retirements that would create new openings? A large cohort of older faculty will be reaching retirement age over the next decade and a half. However, the largest numbers of this group have not yet reached retirement age, and many institutions are cutting positions when faculty retire, rather than make one-for-one replacement hires. The prospect of increasing numbers of retirements holds more promise for the advancement possibilities of those entering the professoriate now, than it does for increasing numbers of new hires at present.

These conflicting trends-fewer academic positions and more new Ph.D.'s-are common to all fields in academia, and are generating increased attention and concern. (E.g., see Holden 1995, 121). Officials at the National Science Foundation acknowledge they have been late in recognizing problems in the job market in the sciences. Anne C. Petersen, deputy director of the National Science Foundation, has noted that NSF is committed to improving its data collection on placement of new Ph.D.'s, and, "In the next few years, she says, the foundation will also direct money to new models of doctoral education, other than the standard one presuming that a Ph.D. will become a professor (Magner 1996b, A19).

APSA, also, will be with the National Academy of Sciences and other major associations in a Convocation on Graduate Education to explore doctoral training and employment issues and their implications for graduate departments, graduate students, and the disciplines. We will report on this initiative and related matters in the future in $P S$.

In the meantime, what should graduate students facing the job search expect, and how might they respond to these conditions? The survey of last year's placement class suggests several things. More students are turning to the nonacademic job market, and future job candidates may want to explore this more carefully, for both international and U.S. positions. One placement officer also suggested that students may want to look more fully at international academic positions, too.

There is evidence as well that job searches will take longer. We find more students reported as repeating on the job market, and many placement officers recommend planning on two years for the job search.

With surprising consistency, the placement officers responding to the placement study this year had the following advice for graduate students entering the job market:

- There is a premium placed on excellence. Ignore advice that in your own case might disrupt doing the best possible work you can. There are ample opportunities for scholars doing the top quality work.

- Finish the Ph.D. or have it substantially completed before entering the job market.

- Start career planning early, look widely at different types of opportunities, hone presentation skills, and develop a breadth of skills including methods and analy- 
sis. Diversify, and develop a strong minor.

- Earn teaching experience and demonstrate promise as a teacher.

- Participate professionally, including presenting papers, publishing in peer-reviewed journals, and obtaining book contracts for one's dissertation.

- Show achievement and balance both in teaching and scholarship.

Finally, thanks should go to the graduate placement officers who volunteer the information for this report and, much more impor- tantly, guide their department's students in job search and placement. The care, concern, and pride they have for their students shows through clearly in these surveys, and ultimately in the quality and character of our discipline.

\section{References}

Brintnall, Michael. 1992. "Affirmative Action: Women and Minorities in the Profession." PS: Political Science \& Politics 25:105-109.
Holden, Constance. 1995. "Careers '95: The Future of the Ph.D." Science, October 6.

Magner, Denise K. 1996a. "The New Generation." Chronicle of Higher Education, February 2.

Magner, Denise K. 1996b. "Universities Debate What They Should Do About Tight Job Market." Chronicle of Higher Education, March 15.

Nelson, Cary. 1995. "Lessons from the Job Wars: What Is to Be Done?" Academe, November-December.

Spellman, Patricia, comp. 1995. "Graduate Students and Faculty Cumulative Data 1985-95." Graduate Faculty and Programs in Political Science 1995-97. Washington, DC: American Political Science Association.

\section{Contributors to APSA Awards and Programs}

George F. Ackerman

Dean Alfange Jr.

Eugene J. Alpert

Bruce E. Altschuler

Jennifer Bailey

Gordon E. Baker

Larry Bartels

William Beaney

Henry Bienen

Richard Brody

Gregory A. Caldeira

Elliot W. Carlson

William A. Carroll

Lief H. Carter

William R. Caspary

Daniel S. Cheever

Bernard C. Cohen

Beverly B. Cook

Christopher J. Deering

Alexander A. Doska

Lee Joan Epstein

Malcolm Feeley

Christopher H. Foreman, Jr.

William E. Frenzel

Kichizo Fujimoto
Jose E. Garriga-Pico Jeff Goodwin

Fred I. Greenstein

Glen Halva-Neubauer

Fredrick C. Harris

Akira Hattori

Jonathan P. Hawley

Miriam R. Jorgensen

Tomoaki Iwai

Joyce E. Keath

Francis J. Keenan

Stanley Kelley Jr.

Steven J. Kelman

David C. King

Alan Kornberg

Samuel Krislov

Lawrence LeDuc

Arend Lijphart

Burdett A. Loomis

Stuart Elaine Macdonald

Ardith L. Maney

David R. Mayhew

Wilson Carey McWilliams

Marian Miller

J. Bernard Moore
F.L. Ted Morton

Walter F. Murphy

Pamela D. Pelletreau

Jack W. Peltason

Steven T. Procopio

John Quirk

George Rabinowitz

Yong-Pil Rhee

Wilbur C. Rich

Ronald Rogowski

Bo Rothstein

Wilma Rule

Barry Rundquist

Paul S. Rundquist

Debra Salazar

Edward Schneier

Robert Y. Shapiro

Roberta S. Sigel

Derek Smiertka

Albert Somit

Ricardo Sucre Heredia

Harold W. Stanley

Alonzo T. Stephens

Grier Stephenson Jr.

Harry P. Stumpf
Ichiro Sunada

Susette M. Talarico

Edward Thompson III

Otto F. Unsinn

Barbara A. Vobejda

Kenneth D. Wald

Price I. Watkins

Curtis C. Wilkie Jr.

David Wilsford

David M. Wilson

Raymond E. Wolfinger

Kazuo Yamauchi

Eleanor E. Zeff

Alan S. Zuckerman

Thank You

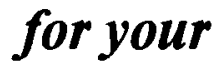

support 